\title{
AN INVERSE FRACTIONAL SOURCE PROBLEM IN A SPACE OF PERIODIC SPATIAL DISTRIBUTIONS
}

\section{ANDRZEJ LOPUSHANSKY, HALYNA LOPUSHANSKA AND OLGA MYAUS}

Abstract. For a time fractional diffusion equation and diffusion-wave equation with Caputo partial derivatives we prove the correctness of an inverse problem. This problem is to find a solution of direct problem, which is classical in time with values in the space of periodic spatial distributions, and a source term of the equation. A time integral over-determination condition is used.

Mathematics subject classification (2010): 35S10.

Keywords and phrases: Fractional derivative, periodic distribution, inverse problem, time integral overdetermination condition.

\section{REFERENCES}

[1] M. M. DJRbashian, A. B. Nersessyan, Fractional derivatives and Cauchy problem for differentials of fractional order, Izv. AN Arm. SSR. Matematika, 3 (1968), 3-29.

[2] Y. Hatano, J. NAKagawa, SH. WAng and M. Yamamoto, Determination of order in fractional diffusion equation, Journal of Math-for-Industry, 5A (2013), 51-57.

[3] A. A. Kilbas, M. Saigo, H-Transforms: Theory and Applications, Boca-Raton: Chapman and Hall/CRC, 2004.

[4] M. KiRAne, S. A. MALiK, Determination of an unknown source term and the temperature distribution for the linear heat equation involving fractional derivative in time, Appl. Math. Comp. 218, Issue $1,163-170$.

[5] A. N. KochubeI, A Cauchy problem for evolution equations of fractional order, Dif. Eqs, 25 (1989), 967-974.

[6] Z. Li, M. YАмамото, Initial boundary-value problems for linear diffusion equation with multiple time-fractional derivatives, arXiv:1306.2778v1[math.AP] 12 Jun 2013, 1-28.

[7] H. LopUshanska, A. LOPUSHANSKy, O. MYAUS, Inverse problem in a space of periodic spatial distributions for a time fractional diffusion equation, Electronic J. of Differential Equations, 2016, 14 (2016), 1-9.

[8] A. O. Lopushansky, The Cauchy problem for an equation with fractional derivatives in Bessel potential spaces, Sib. Math. J., 55, 6 (2014), 1089-1097 - DOI:10.1134/30037446614060111.

[9] YU. LuCHKO, Boundary value problem for the generalized time-fractional diffusion equation of distributed order, Fract. Calc. Appl. Anal., 12, 4 (2009), 409-422.

[10] M. M. Meerschaert, Nane Erkan, P. Vallais amy, Fractional Cauchy problems on bounded domains, Ann. Probab., 37 (2009), 979-1007.

[11] V. A. Mikhailets, A. A. Murach, Hörmander spaces, interpolation, and elliptic problems, Birkhauser, Basel, 2014.

[12] J. Nakagawa, K. Sakamoto And M. Yamamoto, Overview to mathematical analysis for fractional diffusion equation - new mathematical aspects motivated by industrial collaboration, Journal of Math-for-Industry, 2A (2010), 99-108.

[13] H. Pollard, The completely monotonic character of the Mittag-Leffler function $E_{\alpha}(-x)$, Bull. Amer. Math. Soc., 68, 5 (1948), 602-613.

[14] Y. Povstenko, Linear fractional diffusion-wave equation for scientists and engineers, New-York, Birkhauser, 2015, p. 460. 
[15] B. Y. Ptashny K, V. S. Ilkiv, I. Ya. Kmit, V. M. Polishchuk, Nonlocal boundary-value problems for equations with partial derivatives, Kiev, Naukova dumka, 2002.

[16] W. Rundell, X. XU AND L. ZUO, The determination of an unknown boundary condition in fractional diffusion equation, Appl. Anal., 1 (2012), 1-16.

[17] V. S. VLadimirov, Generelized functions in mathematical physycs, Moskow, Nauka, 1979.

[18] A. A. Voroshylov, A. A. Kilbas, Conditions of the existence of classical solution of the Cauchy problem for diffusion-wave equation with Caputo partial derivative, Dokl. Ak. Nauk., 414, 4 (2007), $1-4$.

[19] Y. ZHANG AND X. XU, Inverse source problem for a fractional diffusion equation, Inverse Problems, 27, 3 (2011), 1-12, http://dx.doi.org/10.1088/0266-5611/27/3/035010. 